\title{
Prevalence of functional disability in activities of daily living (ADL), instrumental activities of daily living (IADL) and associated factors, as predictors of morbidity and mortality
}

\author{
José C. Millá n-Calenti a, Javier Tubío a, Salvador Pita-Fernández ${ }^{\text {b }}$, Isabel González-Abraldes a, \\ Trinidad Lorenzo ${ }^{\text {, }}$ Teresa Fernández-Arruty ${ }^{\text {a }}$, Ana Maseda ${ }^{\text {a }}$ \\ “Gerontology Research Group, Department of Medicine, Faculty of Health Sciences, Campus de Oza, E-15006 A Coruña, Spain \\ ${ }^{b}$ Epidemiology Unit, Complejo Hospitalario Universitario, Xubias de Arriba, 84, E-15006 A Coruña, Spain
}

\begin{abstract}
The aim of this study is to establish the existing relationship among variables referred to the person, specifically age and gender, and the functional dependence in basic ADL and in IADL, as well as the possible relationship it has with the increase of morbidity and mortality in a random sample of 598 individuals older than 65 years. Of these individuals, $34.6 \%$ were categorized as dependent for at least one ADL, and 53.5\% if we refer to IADL. Regarding the ADL, the risk of dependence increases (odds ratio $=\mathrm{OR}=1.089)$ per year of age, $(\mathrm{OR}=2.48)$ in women's case; while there is an IADL correlation between age and the score $\left(\mathrm{r}=\_0.527 ; \mathrm{p}<0.001\right)$. A relationship exists between dependence and the days of hospitalization (for ADL: $r={ }_{0} 0.12, \bar{p}=0.018$ and IADL: $r={ }_{0} .97, p=0.003$ ), the number of visits to the doctor (ADL: $\mathrm{r}={ }_{0} 0.27, \mathrm{p}<0.001$; IADL: $\mathrm{r}={ }_{-} 0.25, \mathrm{p}<0.001$ ) or the presence of concomitant pathologies such as dementia (ADL: $\mathrm{p}<0.001$; IADL: $\mathrm{p}<0.001$ ). There is a significant association between age, gender and dependence, as well as between dependence and morbidity and mortality, so that dependence could be used as a predictor of both.
\end{abstract}

Keywords: Dependence, Basic activities of daily living (ADL), Instrumental activities of daily living (IADL), Elderly people, Morbidity, Mortality

\section{Introduction}

Functional capacity refers to the possibility and ability to carry out the daily activities in a normal or accepted way (Millá n-Calenti, 2006). Maintenance of functional capacity is an important indicator of health in the elderly; the loss of this capacity leads to a rise in morbidity and mortality (Stuck et al., 1999).

Disability refers to the negative aspects of the interaction between the individual and the environment, i.e., deficits, limitations in the activity and restrictions in his/her social participation (WHO, 2001). We consider it as dependence when the adaptation of the environment or the use of technical aids cannot compensate disability and the help of a third person is needed to carry out activities of daily living (Conseil de l'Europe, 1998). Dependence is the main impact factor on health and quality of life, not only for the elderly but also for the caregiver and relatives (Millán-Calenti et al., 2000).

Generally, disability in old people is assessed based on their difficulty to carry out the activities of daily living, or those activities everybody does everyday in order to live independently and integrated within the environment (WHO, 2001). The International Classification of Functioning, Disability and Health(ICF) (WHO,2001) tries to establish a consensus in its understanding, by establishing a difference between the basic ADL and the IADL. The first ones (ADL), are defined as those activities essential for an independent life, while carrying out the IADL is more complex, requires a higher level of personal autonomy. These IADL-scores refer to tasks implying enough capacity as to make decisions as well as a greater interaction with the environment. Based on these differences, deficits in the IADL normally precede deficits in the ADL (Judge et al., 1996).

Prevalence of disability has been associated with different factors apart from age and sex (Avlund et al., 1993; Dunlop et al., 1997); thus, a relation has been found with the presence of heart diseases, strokes and diabetes mellitus (Barberger-Gateau and Fabrigoule, 1997; Fried and Guralnik, 1997), with the patient institutionalization and with an increase in morbidity and mortality (Ferrucci et al., 1991; Bavazzano et al., 1998). 
Based on the above arguments, and due to the clear impact disability has on the socio-sanitary system, it is essential to study the prevalence, reasons and effects of disability in the old population in order to draw up a plan for a suitable public health policy (Chalise et al., 2008).

The main purpose of this study was to establish the existing relationship among different variables referred to the person, specifically age and sex, and the functional dependence in basic ADL and IADL; as well as its possible relationship as predictors of morbidity and/or mortality.

\section{Materials and methods}

The representative sample $(n=598)$ consisted of people over 65 years from Narón Council (A Coruña), randomly selected, stratified by quinquennia of age and sex, from the council census. The level of confidence was 95\%; accuracy +- $4 \%$ and estimation for data losses $10 \%$ (Table 1).

Professionals in charge of doing and collecting data were trained to unify criteria. Participants were individually assessed in a Health Center or at home, in the case of people with mobility difficulties. Before the data collection, all participants were informed about the study and signed the corresponding informed consent.

Relating the tools used, the older Americans resources and services (OARS) scale (Duke University, 1978) was used for the socio-demographic and general health status variables, while the ADL (Katz et al., 1963 ) and the IADL (Lawton and Brody, 1969) scores were used to evaluate the functional status.

In order to correlate the different categories established by the ADL with quantitative values regarding dependence, category A has been scored with 6 points, meaning total autonomy; 5 for category $\mathrm{B}, 4$ for $\mathrm{C}$ and $\mathrm{H}, 3$ for $\mathrm{D}, 2$ for $\mathrm{E}, 1$ for $\mathrm{F}$ and 0 for $\mathrm{G}$, which means total dependence.

From the data obtained, a descriptive study was made where the quantitative variables were expressed as mean +- S.D. and the qualitative variables as an absolute value and confidence intervals (CIs). Measurement comparisons were made by means of the Student's t-test and the Mann-Whitney U-test. The association of qualitative variables was estimated by means of the x2-statistics and the correlation among quantitative variables by the calculation of the Spearman r-value. In order to determine which variables modified a dichotomic dependent variable, a multiple logistic regression analysis was made using that dichotomic variable as dependent variable and the other variables introduced in the model as co-variables.

Statistical processing of data was made using SPSS v. 14.0 (SPSS Inc., 2005).

\section{Results}

The average age of the studied population was $75.09+-7.54$ years, which was representative of the sample age group. Regarding sex, women predominated over men $(57.2 \%)$, being significantly older $(\mathrm{p}=$ 0.008 ) than men ( 75.9 years vs. 73.9 years).

Regarding the marital status, $62.1 \%$ were married and $26.1 \%$ were widowers. Among men, $80.8 \%$ were married while only $47.9 \%$ of women were married; men who had widowed represented $10.2 \%$ of the total men and $38.8 \%$ of the women had widowed from the total number of women. It was observed that the marital status is significantly associated to sex (most of the men were married and most of the women were widowers) and age (men who had widowed correspond to a high average age group, of 79.3 years).

Table 1

Distribution of the population and the study sample by age groups and gender in Narón (INE, 2000).

\begin{tabular}{|c|c|c|c|c|}
\hline & \multicolumn{2}{|c|}{ Population } & \multicolumn{2}{|c|}{ Sample } \\
\hline & Males & Females & Males & Females \\
\hline Numbers & 2339 & 3118 & 256 & 342 \\
\hline $65-69$ years & 916 & 957 & 84 & 88 \\
\hline $70-74$ years & 653 & 779 & 73 & 83 \\
\hline $75-79$ years & 415 & 586 & 51 & 67 \\
\hline $80-84$ years & 209 & 400 & 27 & 48 \\
\hline 85 years and over & 146 & 396 & 21 & 56 \\
\hline
\end{tabular}


In relation to the categorization of subjects according to the ADL score (Table 2), we can highlight that $34.6 \%$ of the total subjects studied presented some kind of dependence on the ADL scale; within them, $1.7 \%$ presented dependence for all ADL (category G of Katz et al., 1963) and 21.9\% for at least one (category B). If we analyze the data considering gender, we observe that while $43.9 \%$ of women would be categorized as dependent (they presented dependence in at least one activity), this percentage decreased to $22.3 \%$ when referring to men, $2.9 \%$ of women being totally dependent (category $\mathrm{G}$ ). There were no men with total dependence (category G of Katz et al., 1963). After carrying out a multiple logistic regression analysis grouped by age and sex, we found that, significantly, both age and sex modify the fact of being or not being independent. As the years go on, the risk of dependence increases $(\mathrm{OR}=$ $1.10)$ and this risk is even higher in women's case $(\mathrm{OR}=2.48)$.

Table 3 shows the results referred to each ADL items, regarding the gender. We observe that women are more dependent than men for all assessed activities, highlighting for example, bathing (91.0\% vs. $80.1 \%$ ) or continence $(82.0 \%$ vs. $62.9 \%)$.

Referring to the IADL, Table 4 shows the total values and the values distributed by gender, obtained according to the index categories. Of the sample, $46.5 \%$ are classified as independent, $36.5 \%$ with moderate dependence, $11.5 \%$ with severe dependence and $5.5 \%$ with total dependence. Men present a higher global average score than women (6.2 vs. 5.9), though the difference is statistically not significant $(\mathrm{p}=0.79)$, contrary to the one established in the ADL scores.

After observing the activities assessed according to gender, Table 5 shows the differences found among them; thus, women are more dependent in activities such as handling money (15.8\% are not able to do it against $6.7 \%$ of men) ( $<<0.001)$, or using a means of transport $(7.9 \%$ against $2.3 \%$ of men) $(\mathrm{p}<$ $0.001)$ while men are more dependent in activities such as, for example, doing the laundry $(37.5 \%$ against $23.4 \%$ of women $)(\mathrm{p}=0.001)$.

Also, there is a negative correlation between age and the score obtained with the IADL scale $(\mathrm{r}=+-$ 0.527; $\mathrm{p}<0.001$ ) which is indicative of the association between age and the low IADL scores which would imply the tendency towards dependence; i.e., the older, the more dependent in IADL.

We must highlight the fact that the higher average score ratios obtained in the ADL scale based on the scores obtained by categories (5.56) and IADL (6.67), resulting in a minor dependence, correspond to the group of married people.

Table 2

Functional status category of ADL scores and gender, $\mathrm{n}(\%)$.

\begin{tabular}{|c|c|c|c|}
\hline & Total & Men & Women \\
\hline A (totally independent) & $391(65.4)$ & $199(77.7)$ & $192(56.1)$ \\
\hline B (totally independent except for one) & $131(21.9)$ & $38(14.8)$ & $93(27.2)$ \\
\hline $\mathrm{C}$ (dependent in bathing + another) & $30(5.0)$ & $8(3.1)$ & $22(6.4)$ \\
\hline $\mathrm{D}$ (dependent in bathing + dressing up + another) & $8(1.3)$ & $4(1.6)$ & $4(1.2)$ \\
\hline E (dependent in bathing + dressing up + toileting + another) & $5(0.9)$ & $1(0.4)$ & $4(1.2)$ \\
\hline $\mathrm{H}$ (dependent in at least two activities, but not classified as C, D, E or F) & $2(0.3)$ & $0(0.0)$ & $2(0.6)$ \\
\hline
\end{tabular}

In search of the relation between the functional state with different indicators of physical health and the presence or nonpresence of different pathologies, regarding health indicators, we have found a correlation between the hospital admittance days and the scores obtained in the ADL scale $(r=+-0.12 ; p=0.018)$ and IADL scale $(r=\ldots 0.97 ; p=0.003)$ and between the visits to the family doctor in the past months and the scores obtained (ADL: $r=\ldots 0.27 ; p<0.001$; IADL: $r=+-0.25 ; p<0.001$ ). In relation to the presence of some pathologies, it was observed that lower scores both in ADL and IADL were related with the presence of concomitant pathologies such as Parkinson (ADL: $\mathrm{p}<0.001$; IADL: $\mathrm{p}<0.001$ ), heart failure (ADL: $\mathrm{p}=0.002$; IADL: $\mathrm{p}<0.001)$, cancer (ADL: $\mathrm{p}=0.020$;ADL: $\mathrm{p}=0.012$ ), anemia (ADL: $\mathrm{p}=.035$; IADL: $\mathrm{p}=0.001$ ), stroke (ADL: $\mathrm{p}<0.001$; IADL: $\mathrm{p}<0.001$ ) or finally, dementia (ADL: $\mathrm{p}<0.001$; IADL: $\mathrm{p}<0.001)$. 
Functional assessment by ADL score, according to gender, $\mathrm{n}(\%)$.

\begin{tabular}{lcc}
\hline & Men & Women \\
\hline Bathing & $233(91.0)$ & $274(80.1)$ \\
Independent & $23(9.0)$ & $68(19.9)$ \\
Dependent & & $301(88.0)$ \\
Dressing & $240(93.7)$ & $41(12.0)$ \\
Independent & $16(6.3)$ & $312(91.2)$ \\
Dependent & & $30(8.8)$ \\
Toileting & $248(96.9)$ & $310(90.6)$ \\
Independent & $8(3.1)$ & $32(9.4)$ \\
Dependent & & $249(97.3)$ \\
Transferring & $7(2.7)$ & $15(62.9)$ \\
Independent & & $127(37.1)$ \\
Dependent & $210(82.0)$ & $332(97.1)$ \\
Continence & $46(18.0)$ & $10(2.9)$ \\
Independent & &
\end{tabular}

Table 4

Functional status category by IADL scores according to gender, n(\%).

\begin{tabular}{llll}
\hline & Total & Men & Woman \\
\hline Total independence & $278(46.5)$ & $114(44.5)$ & $164(47.9)$ \\
Moderate dependence & $218(36.5)$ & $111(43.4)$ & $107(31.3)$ \\
Severe dependence & $69(11.5)$ & $25(9.8)$ & $44(12.9)$ \\
Total dependence & $33(5.5)$ & $6(2.3)$ & $27(7.9)$
\end{tabular}

\section{Discussion}

Marital status could be associated with functional disability in the elderly. In our study, as in that made by Tang et al. (1999), married people had less dependence ratios than single people. Nevertheless, it is necessary to go deeper in this aspect before reaching more accurate conclusions.

Regarding the functional capacity and based on our results, approximately $2 / 3(65.4 \%)$ of participants are categorized as independent to carry out ADL, decreasing to $46.5 \%$ when referring to IADL. This data is in concordance with the results obtained in other studies (Nelly-Hayes et al., 1992). On the other hand, the rate of people with functional dependence for one or more ADL (34.6\% in our study) is similar to that obtained in Agüero-Torres et al. (1998) research (32\%). These authors found that $14 \%$ of the people considered as totally independent developed some type of dependence in the following 3 years (age predicting value).

Taking into account the data from the European Community Household Panel survey (ECHP) (Eurostat, 2003) referring to people over 65 in the European Community, it is observed that $21 \%$ of the population is severely deteriorated to carry out activities of daily living, and this figure rises up to $29 \%$ for people over 75 years old. France would be the European country with most dependence in the ADL (28\% of people over 65 ); in contrast to Ireland, with only $8 \%$. In Spain, dependence would reach $22 \%$ of the population over 65 . It is clear that this big difference among figures is due to the socio-economic and cultural differences, as well as to the methodology used (Béland and Zunzunegui, 1999), so homogeneous criteria should be established in order to compare different populations.

In the United States, $10 \%$ of the general population would be dependent to carry out some activities of daily living, which corresponds to $34 \%$ of the population older than 65 (McNeil, 1994).

In our study, $1.7 \%$ were categorized as dependent to carry out all ADL assessed; while 5.5\% were dependent for all IADL. Lázaro Alquezar et al. (2007) found a total dependence prevalence of 9.6\% for $\mathrm{ADL}$ and IADL. 
Functional assessment of IADL score according to gender, n(\%).

\begin{tabular}{|c|c|c|}
\hline & Men & Woman \\
\hline \multicolumn{3}{|l|}{ Ability to use telephone } \\
\hline Operates telephone on own initiative & $215(84.0)$ & $235(68.7)$ \\
\hline Dials well-known numbers & $7(2.7)$ & $19(5.6)$ \\
\hline Answers telephone but does not dial & $18(7.0)$ & $46(13.4)$ \\
\hline Does not use telephone at all & $16(6.3)$ & $42(12.3)$ \\
\hline \multicolumn{3}{|l|}{ Shopping } \\
\hline Takes care of all shopping needs & $170(66.4)$ & $190(55.6)$ \\
\hline Shops independently for small purchases & $49(19.1)$ & $57(16.7)$ \\
\hline Needs to be accompanied on any shopping trip & $13(5.1)$ & $33(9.6)$ \\
\hline Completely unable to shop & $24(9.4)$ & $62(18.1)$ \\
\hline \multicolumn{3}{|l|}{ Food preparation } \\
\hline Plans, prepares and serves adequate meals independently & $144(56.3)$ & $222(64.9)$ \\
\hline Prepares adequate meals if supplied with ingredients & $32(12.5)$ & $42(12.3)$ \\
\hline $\begin{array}{l}\text { Heats, serves and prepares meals, or prepares meals, or prepares meals but does } \\
\text { not maintain adequate diet }\end{array}$ & $31(12.1)$ & $23(6.7)$ \\
\hline Needs to have meals prepared and served & $49(19.1)$ & $55(16.1)$ \\
\hline \multicolumn{3}{|l|}{ Housekeeping } \\
\hline $\begin{array}{l}\text { Maintains house alone or with occasional assistance (e.g., "heavy work } \\
\text { domestic help"') }\end{array}$ & $114(44.5)$ & $184(53.8)$ \\
\hline Performs light daily tasks such as dish washing, bed making & $66(25.8)$ & $72(21.1)$ \\
\hline Performs light daily tasks but cannot maintain acceptable level of cleanliness & $13(5.1)$ & $22(6.4)$ \\
\hline Needs help with all home maintenance tasks & $11(4.3)$ & $17(5.0)$ \\
\hline Does not participate in any housekeeping tasks & $52(20.3)$ & $47(13.7)$ \\
\hline \multicolumn{3}{|l|}{ Laundry } \\
\hline Does personal laundry completely & $144(56.3)$ & $230(67.3)$ \\
\hline Launders small items-rinses stockings, etc & $16(6.2)$ & $32(9.3)$ \\
\hline All laundry must be done by others & $96(37.5)$ & $8(23.4)$ \\
\hline \multicolumn{3}{|l|}{ Mode of transportation } \\
\hline Travels independently on public transportation or drives own car & $208(81.3)$ & $189(55.3)$ \\
\hline Arranges own travel via taxi, but does not otherwise use public transportation & $3(1.2)$ & $10(2.9)$ \\
\hline Travels on public transportation when accompanied by another & $17(6.6)$ & $32(9.3)$ \\
\hline Travel limited to taxi or automobile with assistance of another & $22(8.6)$ & $84(24.6)$ \\
\hline Does not travel at all & $6(2.3)$ & $27(7.9)$ \\
\hline \multicolumn{3}{|l|}{ Responsibility for own medications } \\
\hline Is responsible for taking medication in correct dosages at correct time & $226(88.3)$ & 264(77.2) \\
\hline Takes responsibility if medication is prepared in advance in separate dosage & $13(5.1)$ & $31(9.1)$ \\
\hline Is not capable of dispensing own medication & $17(6.6)$ & $47(13.7)$ \\
\hline \multicolumn{3}{|l|}{ Ability to handle finances } \\
\hline $\begin{array}{l}\text { Manages financial matters independently (budgets, writes checks, pays rent, } \\
\text { bills, goes to bank, etc.), collects and keeps track of income }\end{array}$ & $221(86.3)$ & $237(69.3)$ \\
\hline $\begin{array}{l}\text { Manages day-to-day purchases, but needs help with banking, major purchases, } \\
\text { etc. }\end{array}$ & $18(7.0)$ & $51(14.9)$ \\
\hline Incapable of handling money & $17(6.7)$ & $54(15.8)$ \\
\hline
\end{tabular}

The highest levels of dependence correspond to the IADL since those are activities requiring greater physical integrity and imply the necessity of higher cognitive integrity than the ADL (Béland and Zunzunegui, 1995).

In relation to the ADL, our study showed that "continence", was the activity with higher dependence, in concordance with other studies (Rodríguez-Molinero et al., 2006; Markland et al., 2009). On the other hand, and referring to IADL, housekeeping activities were the most dependent ones, as also found in other researches (Ania Lafuente et al., 1997; Aspiazu Garrido et al., 2002).

If we refer to the differences in gender and ADL, women are normally more dependent than men in all age levels as previous researches have already shown (Strawbridge et al., 1993; Langlois et al., 1996; Oman et al., 1999). In our study, $25.1 \%$ of women showed some type of dependence in the ADL, against only $9.5 \%$ of men. This data complies with those of Melzer et al. (1999) who found figures of $19 \%$ and $11 \%$, respectively, and which, at the same time, reinforce the hypothesis that women, though longevous,

have a worse quality of life. Also, other authors (Alonso et al., 1997; Lyons et al., 1997) establish a higher prevalence of dependence in women when carrying out activities of daily living, being more evident when referring to people over 85 (Lyons et al., 1997; Von Strauss et al., 2003). 
When talking about variable gender and IADL assessed with Lawton index, men present a higher average score than women in our study, which means that in general, they are more independent than women in the assessed areas, though these differences are not strong enough to be considered relevant. But, considering each of the different activities of the index in a separate way and taking into account gender, we can say there are differences among the categories of each item. The greatest differences are found in the activities related to money administration, responsibility in drug intakes and use of means of transport. In these activities, men are less dependent than women. On the other hand, women are more independent than men in activities such as doing the laundry, housekeeping and cooking.

A reason that may explain these results is that, traditionally, women have been more bounded to domestic activities while men have been more bounded to the administration of money. In this sense, we have to remember that one of the Lawton index's weaknesses is, in particular, to include these activities in the assessment of the functional capacity of the elderly (Lázaro Alquezar et al., 2007).

Both our results and those from other authors (Ruigómez and Alonso, 1996; Lozano Yagüe, 2001; Tomás Aznar et al., 2002) show evidence that men are more independent than women for carrying out ADL, corroborating the fact that despite living longer, women spend more time in situation of disability (Dunlop et al., 1997).

We have to mention that, despite the clear evidence, some authors (Boult et al., 1994; Agüero-Torres et al., 1998) do not agree with this opinion, and do not establish any relation between functional dependence and gender, considering that there is no difference between men and women.

Referring to age, as an independent variable from gender, many authors (Guralnik et al., 1993; Artís et al., 2005; Lázaro Alquezar et al., 2007) accept its determinant role in the functional capacity. The loss of capacity to carry out ADL and IADL increases progressively with age, as we have previously demonstrated in our study, where dependence Lawton and Katz scores change as group age increases. As a result, we can say that an advanced age can be the most important risk factor for the deterioration of the functional state in the elderly.

Functional state, age and gender have been used (Carey et al., 2004) to stratify elderly communities in groups with different risk of mortality since, as already proved (Davis et al., 1995; Inouye et al., 1998; Carey et al., 2004), functional disability and dependence are associated with morbidity and mortality in old people.

As observed in other studies (Markides et al., 1996; Black and Rush, 2002; Barrantes-Monge et al., 2007), we have also found that functional dependence correlates both with the number of visits to the family doctor and the days spent in a hospital and also with illnesses of great prevalence in elders (Parkinson, heart failure, dementia, stroke, cancer and anemia).

\section{Conclusion}

Advanced age and female gender are important factors in the development of the disability that leads to dependence. At the same time, an important relation has been observed among health indicators and dependence, being possible to use the last one as predictor of morbidity and mortality in the elder population. Deeper research is needed to determine the relationship among dependence, morbidity and mortality.

\section{Conflict of interest statement}

None.

\section{Acknowledgement}

We sincerely thank Narón Council for giving us access to their elderly people. 


\section{References}

Agüero-Torres, H., Fratiglioni, L., Guo, Z., Viitanen, M., Von Strauss, E., Winblad, B., 1998. Dementia is the major cause of functional dependence in the elderly: 3-year follow-up data from a population-based study. Am. J. Public Health 88,1452-1456.

Alonso, J., Orfila, F., Ruigómez, Ferrer, M., Antó , J.M., 1997. Unmet health care needs and mortality among Spanish elderly. Am. J. Public Health 87, 365-370.

Ania Lafuente, B.J., Suárez Almenara, J.L., Guerra Hernández, L., Santana Santana, A.J., Acosta Morales, C.D., Saavedra Rodríguez, J.M., 1997. Healthy aging and functional disability among the elderly inhabitants of the Canary Islands (Spain). Rev. Esp. Salud Pública 71, 161-171 (in Spanish).

Artís, M., Ayuso, M., Guillén, M., Monteverde, M., 2005. A multiple state model for disability using the decomposition of death probabilities and cross-sectional data. Commun. Stat. Theory Methods 34, 2063-2069.

Aspiazu Garrido, M., Cruz Jentoft, A., Villagrasa Ferrer, J.R., Abanades Herranz, C., García Marín, N., Alvear Valero de Bernabé , F., 2002. Factors related to perceived poor health conditions or poor quality of life among those over 65 years of age. Rev. Esp. Salud Pública 76, 683-699 (in Spanish).

Avlund, A., Schultz-Larsen, K., Kreiner, S., 1993. The measurement of instrumental ADL: content validity and construct validity. Aging Clin. Exp. Res. 5, 371-383.

Barberger-Gateau, P., Fabrigoule, C., 1997. Disability and cognitive impairment in the elderly. Disabil. Rehabil. 19, 175-193.

Barrantes-Monge, M., García-Mayo, E.M., Gutiérrez-Robledo, L.M., Miguel-Jaimes, A., 2007. Dependencia funcional y enfermedades crónicas en ancianos mexicanos. Salud Pública Mex. 49, S459-S466 (in Spanish).

Bavazzano, A.,Magnolfi, S.U., Calvali, D., Valente, C., Boni, F., Baldini, A., Quesada, J.J., 1998. Functional evaluation of Alzheimer patients during clinical trial: a review. Arch. Gerontol. Geriatr. Suppl. 6, 27-32.

Béland, F., Zunzunegui, M.V., 1995. La salud y las incapacidades funcionales. Elaboración de un modelo casual. Rev. Gerontol. 5, 259-273 (in Spanish)

Béland, F., Zunzunegui, M.V., 1999. Predictors of functional status in older people living at home. Age Ageing 28, $153-159$.

Black, S.A., Rush, R.D., 2002. Cognitive and functional decline in adults aged 75 and older. J. Am. Geriatr. Soc. 50, $1978-1986$.

Boult, C., Kane, R.L., Louis, T.A., Boult, L., McCaffrey, D., 1994. Chronic conditions that lead to functional limitation in the elderly. J. Gerontol. 49, M28-M36.

Carey, E.C., Walter, L.C., Lindquist, K., Covinsky, K.E., 2004. Development and validation of a functional morbidity index to predict mortality in community dwelling elders. J. Gen. Intern. Med. 19, 1027-1033.

Chalise, N.H., Saito, T., Kai, I., 2008. Functional disability in activities of daily living and instrumental activities of daily living among Nepalese Newar elderly. Public Health 122, 394-396.

Conseil de l'Europe, 1998. Recommendation num. R(98), du Comité des ministers aux États membres relative a la dependance. Bureau de publications officielles de les Communauté s Européennes. Conseil de l'Europe, Luxemburg (in French).

Davis, R.B., Lezzoni, L.I., Phillips, R.S., Reiley, P., Coffman, G.A., Safran, C., 1995. Predicting in-hospital mortality. The importance of functional status information. Med. Care 33, 906-921.

Duke University, 1978. Multidimensional Functional Assessment: The OARS Methodology. 2nd ed., Duke University, Center for the Study of Aging and Human Development, Durham, NC.

Dunlop, D.D., Hughes, S.L., Manheim, L.M., 1997. Disability in activities of daily living; patterns of change and a hierarchy of disability. Am. J. Public Health 87, 378-383.

Eurostat, 2003. Feasiblity study_comparable statistics in the area of care dependent adults in the European Union, Working Papers and Studies. European Commission, Brussels

Ferrucci, L., Guralnik, J.M., Baroni, A., Tesi, G., Antonini, E., Marchioni, N., 1991. Value of combined assessment of physical health and functional status in community dwelling aged: a prospective study in Florence, Italy. J. Geront. Med. Sci. 46, M52M182.

Fried, L.P., Guralnik, J.M., 1997. Disability in older adults. Evidence regarding significance, etiology and risk. J. Am. Geriatr. Soc. $45,92-100$

Guralnik, J.M., Lacroix, A.Z., Abbott, R.D., Berkman, L.F., Satterfield, S., Evans, D.A., Wallace, R.B., 1993. Maintaining mobility in late life. I. Demographic characteristics and chronic conditions. Am. J. Epidemiol. 137, 845-857.

Inouye, S.K., Peduzzi, P.N., Robison, J.T., Hughes, J.S., Horwitz, R.I., Concato, J., 1998. Importance of functional measures in predicting mortality among older hospitalized patients. J. Am. Med. Assoc. 279, 1187-1193.

INE (Instituto Nacional de Estadística), 2000. Population Demographic Censuses. Municipal Register 2000 (in Spanish).

Judge, J.O., Schechtman, K., Cress, E., Group FISCSIT, 1996. The relationship between physical performance measures and independence in instrumental activities of daily living. J. Am. Geriatric. Soc 44, 1332-1341.

Katz, S., Ford, A.B., Moskowitz, R.W., Jackson, B.A., Jaffe, M.W., 1963. Studies of illness in the age. The index of ADL: a standardized measure of biological and psychological function. J. Am. Med. Assoc. 185, 914-919.

Langlois, J.A., Maggi, S., Harris, T., Simonsick, E.M., Ferrucci, L., Pavan, M., Sartori, L., Enzi, G., 1996. Self-report of difficulty in performing functional activities identifies a broad range of disability in old age. J. Am. Geriatr. Soc. 44, 1421-1428

Lawton, M.P., Brody, E.M., 1969. Assessment of older people: self-maintaining and instrumental activities of daily living. Gerontologist 9, 179-186.

Lázaro Alquezar, A., Rubio Aranda, E., Sánchez Sánchez, A., García Herrero, J.C., 2007. Functional capacity for daily living activities among senior citizens attending community centres in the city of Zaragoza, Spain, 2005. Rev. Esp. Salud Pública 81, 625-636 (in Spanish).

Lozano Yagüe, T., 2001. A methodology to indentify sociosanitary needs on elderly. Rev. Admin. Sanit. 5, 99-114 (in Spanish).

Lyons, R.A., Crome, P., Monaghan, S., Killalea, D., Daley, J.A., 1997. Health status and disability among elderly people in three UK districts. Age Ageing 26, 203-209.

Markides, K.S., Stroup-Benham, C.A., Goodwin, J.S., Perkowski, L.C., Lichtenstein, M., Ray, L.A., 1996. The effect of medical conditions on the functional limitations of Mexican American elderly. Ann. Epidemiol. 6, 386-391.

Markland, A.D., Gerety, M.B., Goode, P.S., Kraus, S.R., Cornell, J., Hazuda, H.P., 2009. Urinary incontinence in communitydwelling older Mexican American and European American women. Arch. Gerontol. Geriatr. 48, 232-237.

McNeil, J.M., 1994. Americans with disabilities: 1991-1992: data from the survey of income and program participation. Current Population Reports, Household Economic Studies, Bureau of the Census.

Melzer, D.,McWilliams, B., Brayne, C., Johnson, T., Bond, J., 1999. Profile of disability in elderly people: estimates from longitudinal population study. Br. Med. J. 318, 1108-1111.

Millán-Calenti, J.C., 2006. Principles of Geriatrics Medicine and Gerontology. McGraw-Hill Interamericana, Madrid (in Spanish) 
Millán-Calenti, J.C., Gandoy-Crego, M., Antelo-Martelo, M., López-Martinez, M., Riveiro-López, M.P., Mayán-Santos, J.M., 2000. Helping the family carers of Alzheimer's patients: from theory to practice. A preliminary study. Arch. Gerontol. Geriatr. 30, $131-138$.

Nelly-Hayes, M., Jette, A.M.,Wolf, P.A., D’Agostino, R.B., Odell, P.M., 1992. Functional limitations and disability among elders in the Framingham study. Am. J. Public Health 82, 841-845.

Oman, D., Reed, D., Ferrara, A., 1999. Do elderly women have more physical disability than men do? Am. J. Epidemiol. 150, 834842.

Rodríguez-Molinero, A., López-Diéguez, M., Tabuenca, A.I., De la Cruz, J.J., Banegas, J.R., 2006. Functional assessment of older patients in the emergency department: comparison between standard instruments, medical records and physicians' perceptions. BMC Geriatr. 6, 13 .

Ruigómez, A., Alonso, J., 1996. Validity of the functional capacity measurement for daily living activities in old people. Rev. Gerontol. 6, 215-223 (in Spanish).

SPSS Inc., 2005. SPSS Base 14.0.1 for Windows Users' Guide. SPSS, Chicago.

Strawbridge, W.J., Camacho, T.C., Cohen, R.D., Kaplan, G.A., 1993. Gender differences in factors associated with change in physical functioning in old age: a 6-year longitudinal study. Gerontologist 33, 603-609.

Stuck, A.E., Walter, J.M., Nikolaous, T., Bu“ la, C.J., Hohmann, C., Beck, J.C., 1999. Risk factors for functional status decline in community living elderly people: a systematic literature review. Soc. Sci. Med. 48, 445-469.

Tang, Z., Wang, H.X., Meng, C., Wu, X.G., Ericsson, K., Winblad, B., Pei, J.J., 1999. The prevalence of functional disability in activities of daily living and instrumental activities of daily living among elderly Beijing Chinese. Arch. Gerontol. Geriatr. 29, $115-125$.

Tomás Aznar, C., Moreno Aznar, L.A., Gérman Bes, C., Alcalá Nalváiz, T., Andrés Esteba, E., 2002. Dependency and unmet need of care in older people in health area of Saragosa, Spain. Rev. Esp. Salud Pública 76, 215-226 (in Spanish).

Von Strauss, E., Agüero-Torres, H., Kareholt, I., Winblad, B., Fratiglioni, L., 2003. Women are more disabled in basic activities of daily living than men only in very advanced ages: a study on disability, morbidity, and mortality from Kungsholmen project. J. Clin. Epidemiol. 56, 669-677.

WHO (World Health Organization), 2001. International Classification of Functioning, Disability and Health (ICF). WHO (World Health Organization), Geneva. 